\title{
ME (Medical Electronics)
}

\section{Kazuo Maeda*}

Department of Obstetrics and Gynecology (Emeritus), Tottori University Medical School, Yonago, Japan

Medicine is composed of Anantomy, Physiology, Pathology, Pharacology and clinical medicine including Obstetrics and Gynecology, but did not include Electronics, which was studied mainly in the Technology Department in old times, while the author selected the electroencephalography (EEG) of eclampsia and preeclampsia as the doctoral thema, though there was no EEG machine in the Department of Obstetrics and Gynecology of Kyushu University in 1949 after the graduation of Kyushu Imperial University Medical School in 1947. The author intended to produce the EEG system by his hand in the EEGgroup of Faculty of Medicine, which was constructed by young doctors of Department of Psychiatry and pharmacology. The EEG system was 2 channel straight amplifiers constructed of vacuum tubes, power source were lead-acid batteries, 6 volts for the tube filaments and 50 volts for the high voltage plate power. A shield room to prevent 60 cycle BAC noise constructed by aluminum plates and wood poles was built in a room of hospital, of which inside was illuminated by a small DC battery lamp. Since there was no commercial pen recorder, multi-channel electro-magnetic optical recorder was used, recording the EEG curve on light-sensitive paper. The amplifier output was monitored by a magic-eye vacuum tube. The patient EEG was studied by hand-made EEG after recording 2 years after providing the system. The eclampsia EEG was recorded in 3 patients in a year. Many preeclamosia cases were studied at the period of time. Deep brain EEG was compared surface one using Kurotsu's electrodes in rabbits. Similar EEGs to the surface was recorded, and the hypertension and proteinura appeared by electric stimulation of Kurotsu sympathetic center located in the hypothalamus, in almost all experiments [1]. The author supposed that preeclampsia was caused by the continuous hypothalamic sympathetic center stimulation with enlarged uterus, but the conduction route of the stimulation was unknown. It was confirmed recently by the reports on the presence of connecting nerve of the uterus and hypothalamus in rats and mice by 4 researchers after 2008. Thus the author reported my study as the cause of preeclampsia 60 years after the original hypothalamic stimulation experiments [2]. Adult ECG, abdominal fetal ECG and fetal PCG were studied using my hand-made amplifiers and ink-writing pen-recorder. It was 1967, when the author introduced ultrasonic Doppler fetal heart beat detector (Smith-Kline, USA), and objectively diagnosed fetal life instead of subjective hearing fetal heart tones, when new objective era was opened in the diagnosis in Obstetrics [3]. The first ultrasonic Doppler fetal arterial blood flow curve was recorded by a hand-made Doppler frequency demodulation device. The first CTG monitor of fetal heart rate (FHR) recorded by fetal heart sound and uterine contraction was produced by the collaboration of TUITU and reported in 1965 in Japan [4]. The fetal ECG, PCG, CTG, quantitative FHR analysis, Doppler method, fetal blood flow curve, fetal acid-base balance, their relation to fetal outcome, and so on, were reported in my special lecture of Japan Society of Obstetrics and Gynecology entitled as Pathophysiology of Fetus in 1969 [5]. The presence of safe ultrasound output intensity was confirmed in the group studies on the ultrasound bioeffect and safety in 1976, of which details will be published in further JHMI article. A new ultrasound Doppler fetal movement was recorded by the actocardiogram, which was also established by the author's hand-made devices in 1984 [6]. The medical electronic ideas disclosed the origin of FHR acceleration and variability, and their application in the studies on fetal brain damage [7]. Also regular uterine contraction in the labor was estimated to be the biological oscillation caused by the positive feedback system composed of hypothalamus, hypophysis, oxytocin, circulation, uterine contraction, and nerves distributed between the uterus and hypothalamus. New ideas were frequently induced by the knowledge of medical electronics.

\section{References}

1. Maeda K (1954) Electroencephalographic studies on eclampsia and preeclampsia. ActaObstetGynecolJpn 6: 75-99.

2. Maeda K (2013) Preeclampsia is caused by continuous sympathetic excitation due to an enlarged pregnant uterus. J Perinat Med.

3. Maeda K, Nakano H (1968) Experiences with the technique of ultrasonic Doppler method in obstetrics. J Jap ObstetGynecolSoc15: 135-142.

4. Maeda K (1965) Studies on the fetal cardiotachography during labor. V International Conference on Medical Electronics and Biological Engineering, Tokyo.

5. Maeda K, Kimura S, Nakano H (1969) Pathophysiology of Fetus.Fukuoka, Fukuoka Printing.

6. Maeda K (1984) New ultrasonic Doppler fetal actograph and continuous recording of fetal movement. Nihon SankaFujinkaGakkaiZasshi36:280-288.

7. Maeda K (2012) Actocardiographic analysis of fetal hypoxia detected by the bradycardia, loss of fetal heart rate acceleration and long term variability. $J$ Health Med Inform.

*Corresponding author: Kazuo Maeda, Department of Obstetrics and Gynecology (Emeritus), Tottori University Medical School, Yonago, Japan, 3-125, Nadamachi, Yonago, Tottoriken, 6830835, Japan, Tel: 81-859-22-6856; Fax: 81-859-22-6856; E-mail:maeda@mocha.ocn.ne.jp

Received November 22, 2013; Accepted November 23, 2013; Published November 28, 2013

Citation: Maeda K (2013) ME (Medical Electronics). J Health Med Informat. 5: e119. doi:10.4172/2157-7420.1000e119

Copyright: () 2013 Maeda K. This is an open-access article distributed under the terms of the Creative Commons Attribution License, which permits unrestricted use, distribution, and reproduction in any medium, provided the original author and source are credited. 